\title{
TAK-242 Protects Against Apoptosis in Coronary Microembolization-Induced Myocardial Injury in Rats by Suppressing TLR4/NF-kB Signaling Pathway
}

\author{
Xian-tao Wang Yuan-xi Lu Yu-han Sun Wen-kai He Jia-bao Liang Lang Li \\ Department of Cardiology, the First Affiliated Hospital of Guangxi Medical University, Nanning, China
}

\section{Key Words}

Coronary microembolization • TAK-242 • TLR4 • Apoptosis

\begin{abstract}
Background/Aims: Myocardial apoptosis is heavily implicated in the myocardial injury caused by coronary microembolization (CME), and toll-like receptor 4 (TLR4) is considered to be involved in this apoptotic cascade. Therefore, the present study was designed to investigate the role of TLR4/NF-KB signaling pathway regulated by TAK-242, a selective TLR4 signal transduction inhibitor, in the myocardial apoptosis after CME in rats. Methods: Fortyfive rats were randomized (random number) into three groups: sham, CME and CME + TAK242 ( $n=15$ per group).CME was induced by injecting polyethylene microspheres $(42 \mu \mathrm{m})$ into the left ventricular except the sham group. CME + TAK-242 group was treated with TAK-242 $(2 \mathrm{mg} / \mathrm{kg})$ via the tail vein 30 minutes before CME modeling. Cardiac function was evaluated 6 hours after operation. Tissue biopsy was stained with HBFP to measure the size of microinfarction area. TUNEL staining was used to detect myocardial apoptosis. Western blot and qPCR were used to evaluate the expression of TLR4, MyD88, NF-KB p65, p-IKB $\alpha$ and Cleaved caspase-3. Results: Cardiac function in the CME group and CME + TAK-242 group were significantly decreased compared with the sham group $(P<0.05)$ and the micro-infarction area, the apoptotic index, the expression of TLR4, NF-KB p65, p-IKB $\alpha$ and Cleaved caspase-3 were increased significantly $(P<0.05)$. Cardiac function in the CME + TAK-242 group was significantly improved compared with the CME group $(P<0.05)$ and the micro-infarction area, the apoptotic index, the expression of TLR4, MyD88, NF-KB p65, p-IkB $\alpha$ and Cleaved caspase-3 were decreased significantly $(P<0.05)$. Conclusions: TAK-242 can effectively improve CMEinduced cardiac dysfunction by regulating TLR4/NF-KB signaling pathway and then reducing the myocardial apoptosis.
\end{abstract}




\section{Introduction}

Coronary microembolization (CME) was first identified at autopsy of patients dying from a sudden cardiac event [1]. As one of unfavorable complications of percutaneous coronary intervention (PCI), CME may result in myocardial micro-necrosis, cardiac dysfunction, arrhythmias, and coronary reserve reduction [2-4]. It is responsible for the lost benefit of reperfusion therapy, including thrombolytic therapy and coronary interventions. Considerable efforts have been made to prevent and treat CME, but it appears to have little effect [5-7]. Recently, some researches showed that myocardial apoptotic process may underlie the molecular mechanism of CME-induced myocardial injury [8, 9]. Apoptosis inhibition may delay the progression of chronic cardiac dysfunction following CME and improve the prognosis [10].

Toll-like receptors play a pivotal role in host immune defense against invading pathogens and endogenous danger signals in various tissues including the heart [11, 12]. Toll-like receptor 4 (TLR4) has been demonstrated to mediate myocardial ischemia reperfusion injury, maladaptive left ventricular remodeling and increased area of myocardial infarction [13, 14]. Some researches showed that TLR4 signaling pathway may be a promising therapeutic target for the treatment of atherosclerotic cardiovascular diseases [15-17]. In our previous vitro study, we found that the activation of TLR4/ NF- $\mathrm{KB}$ signaling pathway trigger the apoptotic cascades and pretreatment with TAK-242, a selective TLR4 signal transduction inhibitor, then significantly suppressed cardiomyocyte apoptosis [18]. A better molecular understanding of these apoptotic properties in vivo is critical in understanding CME-induced myocardial injury and future treatment.

In the present study, we established a rat model of CME and hypothesized that treatment with TAK-242 would improve cardiac function by inhibiting the activation of TLR4/ NF- $\mathrm{KB}$ signaling pathway and the consequent apoptotic cascades.

\section{Materials and Methods}

\section{Animal Modeling and Grouping}

All animal procedures were conducted in accordance with the Guide for the Care and Use of Laboratory Animals (NIH Publication No. 85-23) and were approved by the Animal Care and Use Committee of Guangxi Medical University. Adult male Sprague-Dawley rats (250-300g) were provided by the Medical Experimental Animal Center of Guangxi Medical University (Nanning, China). Forty-five rats were randomized (random number) into three groups: sham, CME and CME plus TAK-242 ( $n=15$ per group). The present study established a CME model by injecting plastic microspheres into the left ventricle (LV), as previously described $[19,20]$. Briefly, a left lateral thoracotomy was undertaken in rats at the third and fifth intercostal space. The pericardium was opened and the ascending aorta was exposed fully. A suspension of microspheres in saline solution containing about 3000 microspheres (42 $\mu \mathrm{m}$ in diameter, Biosphere Medical Inc. Rockland, USA) was injected into the LV during 10s occlusion of the ascending aorta. Rats in the CME plus TAK-242 group received an intravenous injection of TAK-242 (2 mg/kg, MedChem Express, Princeton, USA) via the tail vein $30 \mathrm{~min}$ before surgery [21], and rats in the sham group received an injection of the same volume of normal saline only.

\section{Cardiac Function Monitoring}

Our previous research revealed that cardiac function reached the poorest at $6 \mathrm{~h}$ after CME, so we selected that time point to detect the cardiac function parameters [22].

All echocardiographic examinations including left ventricular ejection fraction (LVEF), left ventricular fractional shortening (FS), cardiac output (CO) and left ventricular enddiastolic diameter (LVEDd) of the rats in each group were performed at a probe frequency of $10 \mathrm{MHz}$ by an experienced professional physician. All measures were expressed as the average of three heart beat cycles. 


\section{Cellular Physiology Cell Physiol Biochem 2017;41:1675-1683

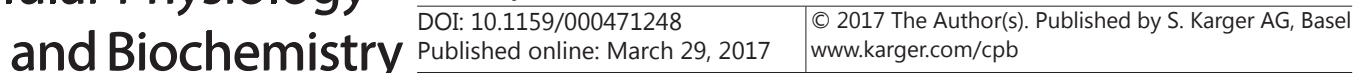

Wang et al.: Effects of TAK-242 on CME-Induced Myocardial Injury

Tissue sampling and sample treatment

After cardiac function detection, the hearts were arrested by injecting $2 \mathrm{~mL} \mathrm{10 \%} \mathrm{potassium} \mathrm{chloride}$ into the tail vein. The hearts were isolated and cleaned with cold normal saline immediately. The atrial appendage and atrium cordis were removed, and parts of heart ventricle were rapidly frozen in liquid nitrogen and stored at $-80^{\circ} \mathrm{C}$ for western blot analysis and qPCR. The others were fixed in $4 \%$ paraformaldehyde for $12 \mathrm{~h}$, embedded in paraffin and serially sectioned into slices of $4 \mu \mathrm{m}$ thickness for TUNEL staining and hematoxylin-basic fuchsin-picric acid (HBFP) staining.

\section{Myocardial micro-infarct size measurement}

Early myocardial ischemia or infarct region can be detected by HBFP staining. The normal myocardial tissue was dyed yellow or brown while the ischemia or necrotic myocardial tissue red. A DMR-Q550 pathological image analyzer (Leica, Germany) was used to analyze HBFP-stained slices. Briefly, five microscopic visual fields (magnification, $\mathrm{x}$ 100) were randomly sampled from each slice for observation using Leica Qwin analysis software. The area of micro-infarction was determined by planimetry and expressed as percentage of the total analyzed area.

Apoptosis assay

Apoptotic cardiomyocytes were detected using TUNEL assay kit (Roche, USA). TUNEL staining was performed according to the manufacturer's instructions. The apoptotic nuclei were stained yellow-brown while the normal light blue. In each slice,10 random high-power fields (magnification, $\mathrm{x} 400$ ) were observed to count TUNEL-positive nuclei, and the myocardial apoptotic index was calculated as the number of TUNELpositive cell nuclei / total nuclei $\times 100 \%$.

\section{RNA extraction and Quantitative RT-PCR}

Total RNA was extracted from cardiac tissue using the TRIzol reagent (Gibco, USA) according to the protocols supplied by the manufacturers. The concentration of RNA was quantified by a NanoDrop (Thermo Fisher Scientific Inc., USA) and then subjected to reverse transcription using a cDNA reverse transcription kit (TaKaRa, Japan) according to the manufacturer's instructions. Then, the obtained cDNA was subjected to RT-qPCR for TLR4 mRNA using a SYBR Green I PCR kit (TaKaRa, Japan). The conditions for all RT-qPCR reactions were performed on the ABI PRISM 7500 system (Applied BioSystems, USA). The sequences of the primers were designed as follows: TLR4 forward: $5^{\prime}$-AAGTTATTGTGGTGGTGTCTAG-3' and reverse: 5'-GAGGTAGGTGTTTCTGCTAAG-3'; GAPDH forward: 5'-TGCACCACCAACTGCTTAG-3' and reverse: $5^{\prime}$-GATGCAGGGATGATGTTC-3'. The relative quantification of TLR4 mRNA expression was calculated using the $2^{-\Delta C \mathrm{Ct}}$ method and was normalized to GAPDH.

\section{Western blotting}

The protein samples were extracted from cardiac tissue blocks with Protein Extracion Kit (Solarbio, Beijing, China). The protein concentrations were determined by using a bicinchoninic acid (BCA) protein assay (Beyotime Biotechnology, Jiangsu, China). Each sample containing equal amounts (50 $\mu \mathrm{g}$ ) of protein was loaded on 10\% SDS-PAGE and transferred to a PVDF membrane (Millipore). After blocking with 5\% non-fat milk in TBS for $1 \mathrm{~h}$ at room temperature, membranes were incubated with the following primary antibodies in dilution buffer overnight at $4{ }^{\circ} \mathrm{C}$ : anti-TLR4, anti-MyD88, anti-NF- $\mathrm{KB}$ (p65), anti-p-IKB $\alpha$, anticleaved caspase-3, anti-Histone-H3 and anti-GAPDH (all from Abcam, Cambridge, USA). GAPDH was used as an internal control and Histone-H3 was used as a nuclear protein loading control. After washing 3 times in TBST, the membranes were incubated with goat anti-mouse horseradish peroxidase (HRP)-conjugated secondary antibodies (KeyGEN BioTECH, Nanjing, China) in dilution buffer for $2 \mathrm{~h}$ at room temperature. Then, antigen-antibody complex was visualized using the enhanced chemiluminescence (ECL) method. Immunoblots were exposed to X-ray film and images were taken using an imaging system (Bio-Rad, USA). At last, the results were analyzed using the Quantity One software (Bio-Rad).

\section{Statistical analysis}

All data are presented as mean \pm standard deviation (SD). Differences between multiple groups were analyzed by one-way ANOVA followed by Student-Neuman-Keuls or Dunnett test, using Prism software (GraphPad Prism version 5.0). All experiments were performed independently in triplicate. Values of $P<$ 0.05 were considered as statistically significant. 


\section{Cellular Physiology Cell Physiol Biochem 2017;41:1675-1683

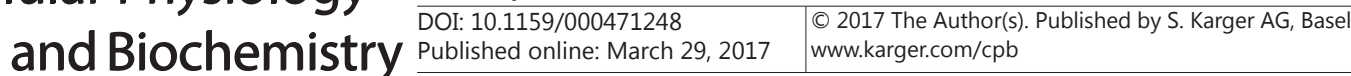

Wang et al.: Effects of TAK-242 on CME-Induced Myocardial Injury

\section{Results}

\section{Changes in cardiac function}

Compared to the sham group, cardiac dysfunction was induced following CME, characterized by increased LVEDD as well as decreased LVEF, FS, and CO $(P<0.05)$ as summarized in Table 1 . Pretreatment with TAK-242 significantly improved cardiac function following CME, as compared to the CME model group $(P<0.05)$. These results suggest that pretreatment with TAK-242 improves cardiac function in this rat model of CME.

\section{Micro-infarct Following CME}

HBFP staining was performed to determine the presence of myocardial micro-infarction (Fig. 1). No micro-infarct was found in the sham group, while it was significantly evident in the CME group $(P<0.05)$. TAK-242 pretreatment group significantly reduced the microinfarction area, as compared to the CME model group ( $8.58 \pm 2.12$ vs. $14.65 \pm 4.23, P<0.05)$.

\section{Myocardial apoptosis following CME}

TUNEL staining was conducted to confirm myocardial apoptosis. The myocardial apoptotic index in the sham, CME and CME plus TAK-242 groups were $1.90 \pm 0.80 \%, 33.6 \pm 6.30$ $\%$ and $14.3 \pm 5.10 \%$, respectively (Fig. 2). The apoptotic index was significantly enhanced in the CME group compared with the sham group $(P<0.05)$. TAK-242 pretreatment significantly reduced apoptotic index $(P<0.05)$.

\section{Expression of TLR4 $\mathrm{mRNA}$}

RT-qPCR analysis was performed to observe the expression of TLR4 mRNA in rat myocardial (Fig. 3). Compared with the rats from the sham group, those from the CME group showed significantly enhanced expression of myocardial TLR4 mRNA after CME modeling $(P<0.05)$. Meanwhile, the mRNA levels of TLR4 were significantly down-regulated by pretreatment with TAK-242 $(P<0.05)$. The results of western blot analysis were consistent with RT-qPCR analysis (Fig. 4).

Table 1. Effects of TAK-242 on cardiac function following CME. Abbreviations: CME, coronary microembolization; LVEF, left ventricular ejection fraction; FS, left ventricular fractional shortening; CO, cardiac output; LVEDd, left ventricular enddiastolic diameter. Data are presented as mean \pm S.D. ${ }^{a} P<0.05$ versus the sham group; ${ }^{\mathrm{b}} P<0.05$ versus the CME group

\begin{tabular}{lccccc}
\hline Group & $n$ & $\operatorname{LVEF}(\%)$ & FS(\%) & CO(L/min $)$ & LVEDd(mm) \\
\hline Sham & 15 & $84.80 \pm 2.51$ & $41.65 \pm 1.12$ & $0.218 \pm 0.018$ & $5.26 \pm 0.37$ \\
CME & 15 & $68.91 \pm 4.12^{\mathrm{a}}$ & $22.68 \pm 2.54^{\mathrm{a}}$ & $0.103 \pm 0.025^{\mathrm{a}}$ & $7.69 \pm 0.51^{\mathrm{a}}$ \\
CME+TAK-242 & 15 & $75.58 \pm 5.01^{\mathrm{ab}}$ & $33.21 \pm 3.04^{\mathrm{ab}}$ & $0.155 \pm 0.031^{\mathrm{ab}}$ & $6.43 \pm 0.18^{\mathrm{ab}}$ \\
\hline
\end{tabular}

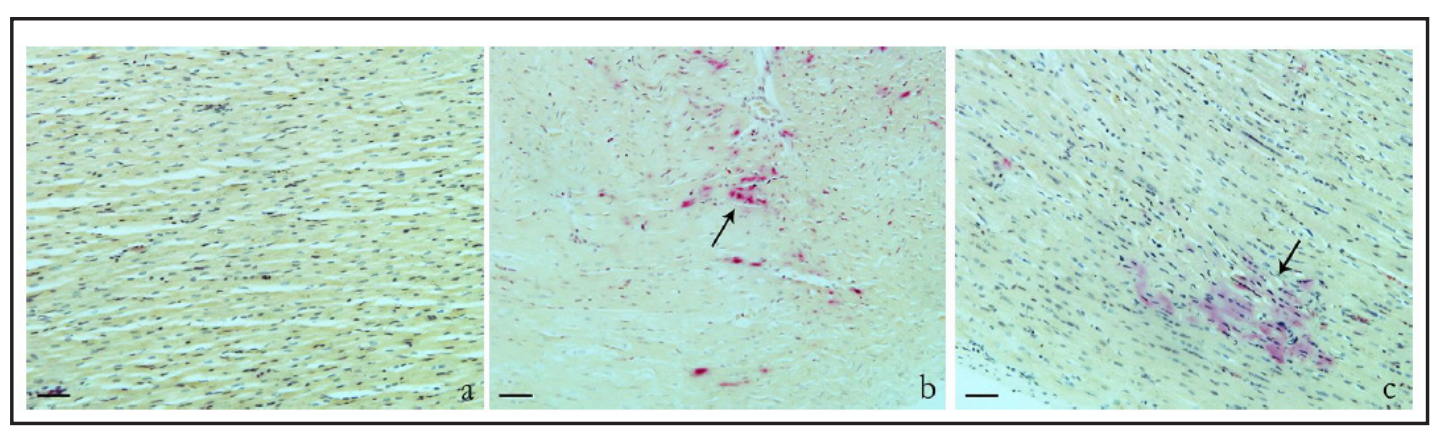

Fig. 1. Micro-infarct measurement with HBFP staining (magnification, $x 200$; Scale bar $=50 \mu \mathrm{m}$ ). The normal myocardium was stained yellow, while the ischemic myocardium was stained red. Arrows indicate micro-infarct focus. a, Sham group; b, CME group; c, CME+TAK-242 group. 
A
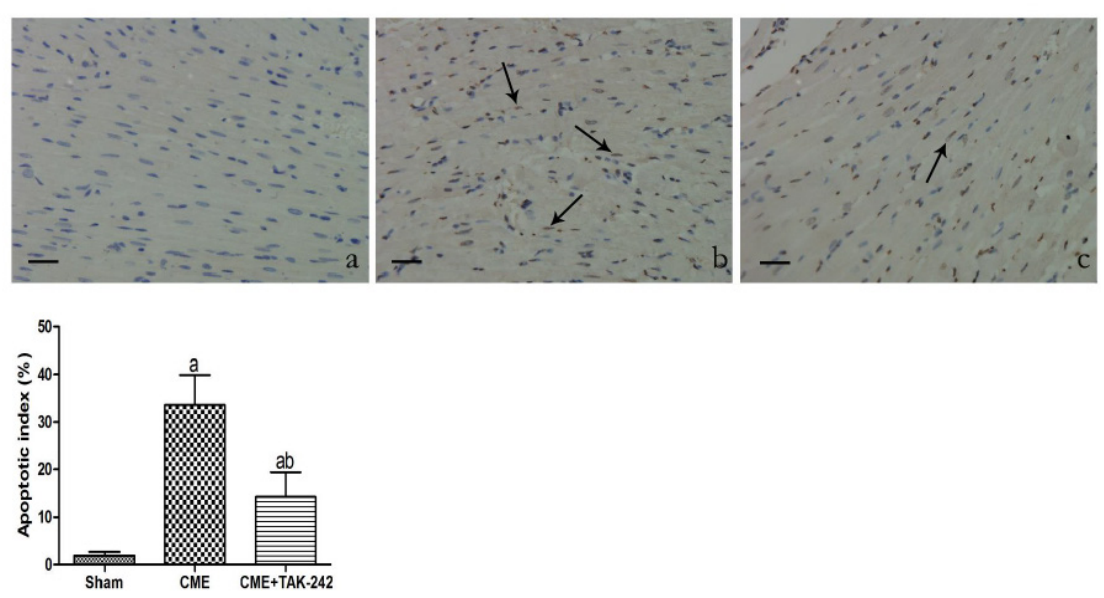

Fig. 2. Apoptosis detected by TUNEL staining (magnification, $\mathrm{x} 400$; Scale bar $=25 \mu \mathrm{m}$ ). A, Apoptotic nuclei were stained yellow-brown while the normal cell nuclei light blue. The arrow indicates TUNEL-positive nucleus. a, Sham group; b, CME group; c, CME+TAK-242 group. B, Changes of apoptotic index in each group. The data were obtained from at least three independent experiments and the values represent the means \pm S.D. ${ }^{\text {a }} P<0.05$ versus the sham group; ${ }^{b} P<0.05$ versus the CME group.

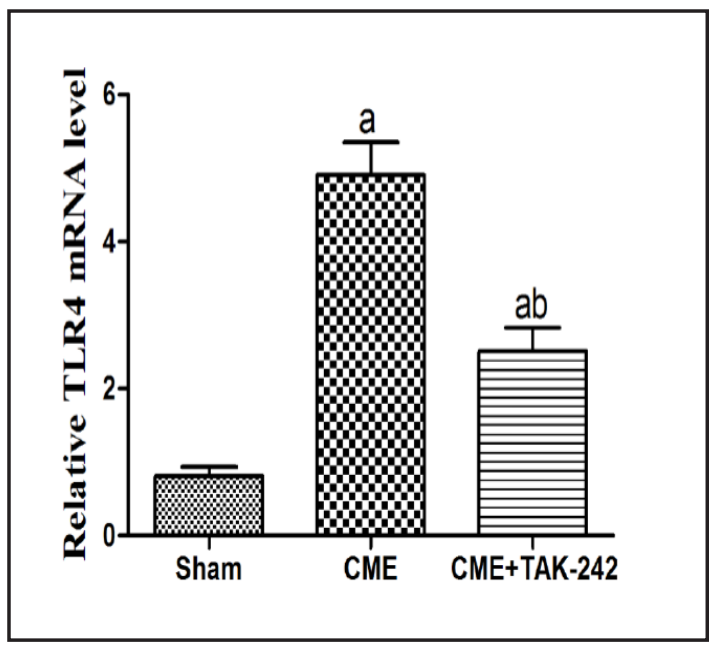

Fig. 3. TLR4 mRNA expression detected by RT-qPCR. The data were obtained from at least three independent experiments and the values represent the means \pm S.D. ${ }^{a} P<0.05$ versus the sham group; ${ }^{b} P<0.05$ versus the CME group.

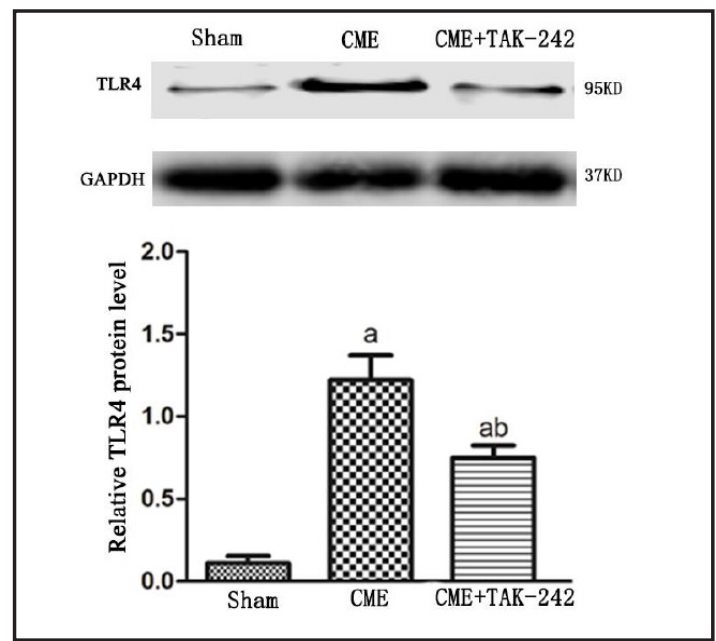

Fig. 4. TLR4 protein expression detected by western blot. The data were obtained from at least three independent experiments and the values represent the means \pm S.D. ${ }^{\mathrm{a} P}<0.05$ versus the sham group; ${ }^{\mathrm{b}} P<$ 0.05 versus the $\mathrm{CME}$ group.

Expression of TLR4, MyD88, NF- $\kappa B$ p65, $p$-I $\kappa$ B $\alpha$ and Cleaved caspase-3 proteins

MyD88 and NF- $\kappa B$ are the downstream effectors of TLR4 signaling pathway, accordingly, the MyD88 and NF- $\mathrm{KB}$ activation were investigated by western blot analysis (Fig. 5 and 6). Caspase-3 is one of the most important mediators of apoptosis, therefore, we determined the activity of caspase- 3 by western blot. Our results showed that protein levels of TLR4, MyD88, NF- $\kappa \mathrm{B}$ p65(nuclei), $\mathrm{p}-\mathrm{I} \kappa \mathrm{B} \alpha$ and cleaved caspase- 3 markedly increased after CME compared with the sham group (Fig. 7 and 8 , all $P<0.05$ ). Furthermore, pretreatment with

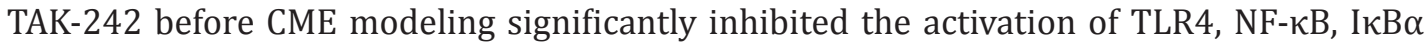
and caspase- 3 compared to CME group (all $P<0.05$ ).

\section{KARGER}




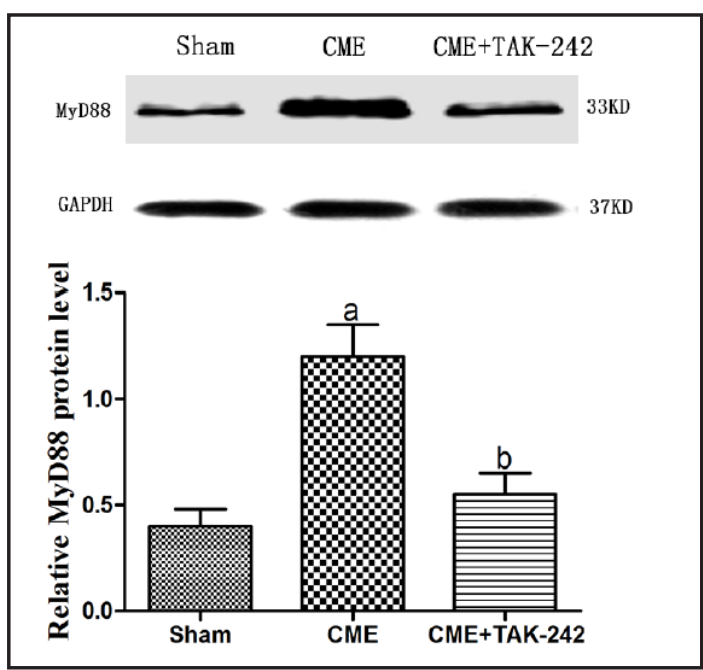

Fig. 5. MyD88 protein expression detected by western blot. The data were obtained from at least three independent experiments and the values represent the means \pm S.D. ${ }^{\text {a }} P<0.05$ versus the sham group; ${ }^{\text {b } P}$ $<0.05$ versus the CME group.

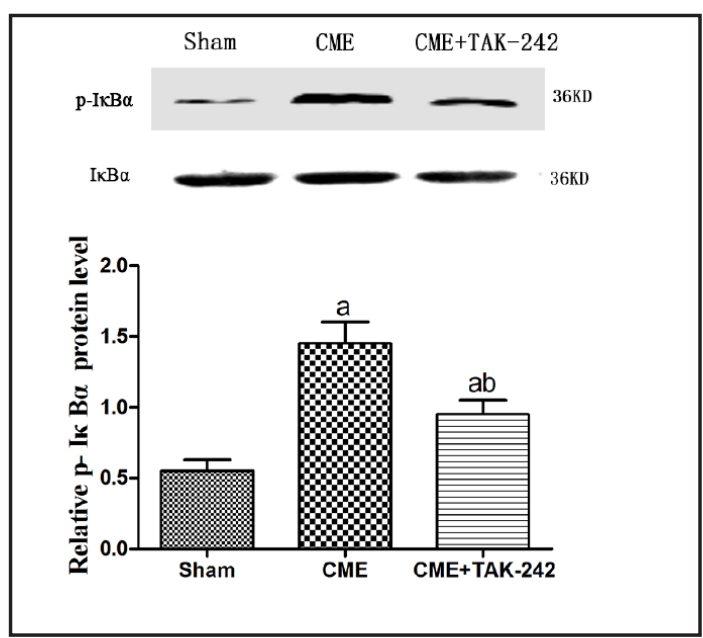

Fig. 7. $\mathrm{p}-\mathrm{I \kappa} B \alpha$ protein expression detected by western blot. The data were obtained from at least three independent experiments and the values represent the means \pm S.D. ${ }^{\text {a }} P<0.05$ versus the sham group; ${ }^{\mathrm{b}} P<0.05$ versus the CME group.

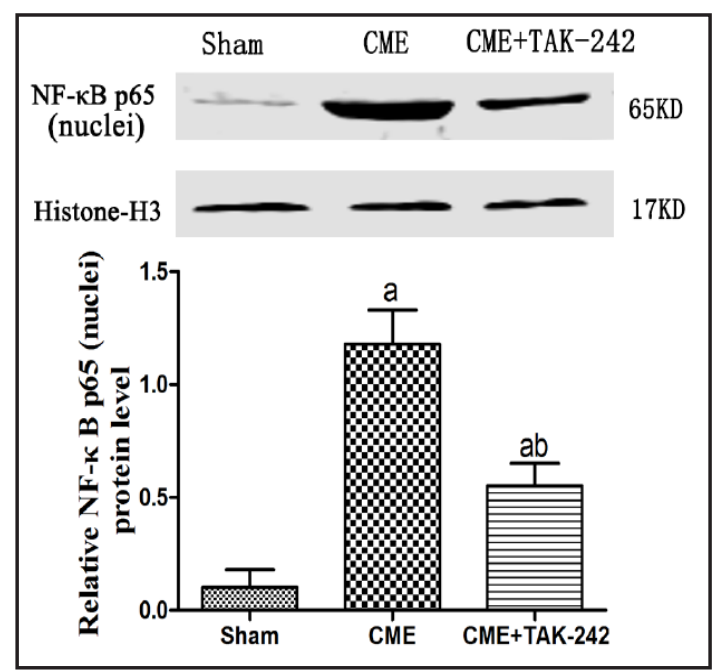

Fig. 6. NF- $\mathrm{BB}$ p65 (nuclei) protein expression detected by western blot. The data were obtained from at least three independent experiments and the values represent the means \pm S.D. ${ }^{\text {a }} P<0.05$ versus the sham group; ${ }^{\mathrm{b}} P<0.05$ versus the CME group.

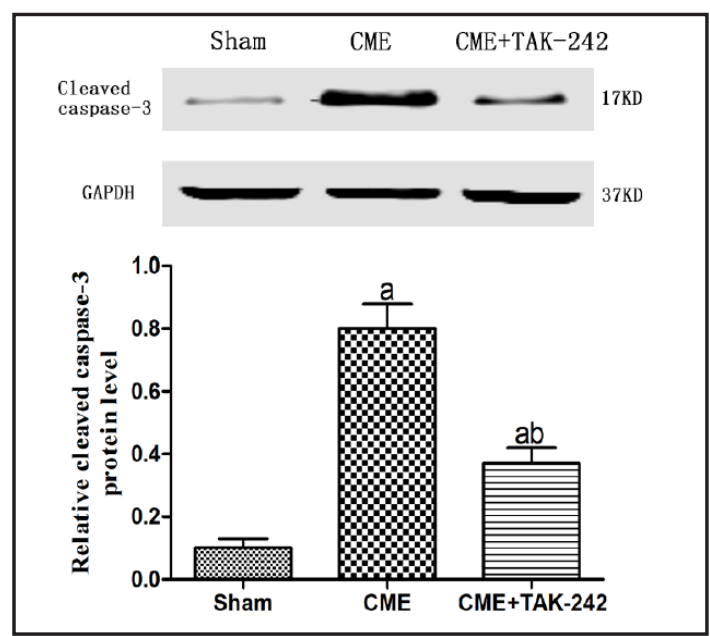

Fig. 8. Cleaved caspase-3 protein expression detected by western blot. The data were obtained from at least three independent experiments and the values represent the means \pm S.D. ${ }^{a} P<0.05$ versus the sham group; ${ }^{\mathrm{b}} P<0.05$ versus the CME group.

\section{Discussion}

The present study was designed to explore the role of TLR4/NF- $\kappa B$ signaling pathway regulated by TAK-242 in the myocardial apoptosis after CME in rats. The results revealed that cardiac dysfunction, micro-infarct and apoptosis were induced following CME. Additionally, our results showed that the activation of TLR4/NF- $\kappa B$ signaling pathway was a potential mechanism for CME-induced myocardial apoptosis in rats. The TLR4 inhibitor, TAK-242, effectively improved CME-induced cardiac dysfunction by regulating TLR4/NF- $\kappa$ B signaling pathway and then reducing the myocardial apoptosis. 
CME is defined as coronary microcirculation thrombosis and micro-infarction caused by atherosclerotic plaque rupture or microemboli in patients undergoing PCI [3]. It may occur spontaneously in patients with acute coronary syndromes or artificially during thrombolytic therapy and coronary interventions, resulting in serious sequelae such as malignant arrhythmias, contractile dysfunction and even sudden cardiac death $[1,23]$.

Toll-like receptors play a pivotal role in host immune defense against invading pathogens and endogenous danger signals in various tissues including the heart[11, 12].TLR4 has been demonstrated to mediate myocardial ischemia reperfusion injury, maladaptive left ventricular remodeling and increased infarct size after myocardial infarction[13, 14, 24, 25]. Some research findings suggest that the activation of TLR4 signaling pathway is considered to be a promising therapeutic target for the treatment of atherosclerotic cardiovascular diseases[16, 26, 27]. In the present study, we revealed that the mRNA and protein levels of TLR4 were up-regulated after CME in rats.

In this study, CME-induced myocardial apoptosis is reduced by pretreatment with TAK242, an exogenous synthetic antagonist for TLR4, suggesting that the TLR4 pathway plays a critical role in CME-induced apoptosis. Apoptosis in the present study was documented by TUNEL staining. The results were consistent with characteristic changes of cleaved caspase- 3 protein, a marker of apoptosis.

MyD88 and NF- $\kappa$ B are the downstream effectors of TLR4, which regulate the expression of many inflammatory genes and participate in the development of atherosclerosis [28, 29]. NF- $\kappa B$ activation is pivotal in the transcription and translation of caspases expression. In addition, NF- $\kappa \mathrm{B}$ plays a crucial role in cardiac pathological processes via regulating expression of many genes that are involved in apoptosis of cardiomyocytes [30]. Research data in vitro and vivo suggested the potential importance of TLR4/NF- $\kappa B$ pathway in myocardial ischemia-reperfusion injury [27, 30]. Therefore, inhibition of TLR4-mediated NF- $\kappa B$ activation could be an important approach for attenuation of cardiac dysfunction.

Caspases play a vital role in the regulation and execution of apoptosis. We determined the activation of caspase- 3 in the present study to examine downstream apoptotic signaling during CME-induced apoptosis. Caspase-3 catalyzes a terminal step in apoptosis, and its activation may serve as a marker of apoptosis in heart [31]. The results of the present study showed that CME significantly increased the activation of caspase-3 in rat hearts.

The present study predominantly focused on CME induced myocardial injury and investigated the possible underlying mechanisms. CME induced myocardial injury was shown to be associated with TLR4/NF- $\kappa B$ signaling pathway activation induced myocardial apoptosis. These findings may provide new therapeutic options for myocardial injury in CME-induced cardiac dysfunction.

For better interpretation of the results, some limitations in this study should be acknowledged. First, the results were derived from rat CME model which was made by injecting plastic microspheres into the LV. Therefore, the current results may not be directly comparable with those obtained in vivo microembolization in patients. Second, we only investigated the short-term protective effects of TAK-242. Thus, it is uncertain how long would this protective effect sustain. Considering of this, future studies are therefore required to explore in more accurately mimic animal model.

In conclusion, our results indicate that CME induces myocardial apoptosis in a rat model via the activation of TLR4/NF- $\kappa B$ signaling pathway. TAK-242 can effectively improve CME-induced cardiac dysfunction by regulating TLR4/NF- $\kappa B$ signaling pathway and then reducing the myocardial apoptosis.

\section{Acknowledgements}

This work was supported by Appropriate Technology for Health Care Research and Development Projects of Guangxi, China (Grant No. S2015 21) , National Natural Science 


\section{Cellular Physiology Cell Physiol Biochem 2017;41:1675-1683 \\ \begin{tabular}{ll|l} 
DOI: 10.1159/000471248 & Ond 2017 The Author(s). Published by S. Karger AG, Basel \\
www.karger.com/cpb
\end{tabular}}

Wang et al.: Effects of TAK-242 on CME-Induced Myocardial Injury

Foundation of China (Grant No.81600283) and Guangxi Natural Science Foundation (Grant No. 2016GXNSFBA380022).

\section{Disclosure Statement}

No competing financial interests exist for any of the authors.

\section{References}

1

Erbel R, Heusch G: Coronary microembolization. J Am Coll Cardiol 2000;36:22-24.

Camici PG, Crea F: Medical progress - Coronary microvascular dysfunction. New Engl J Med 2007;356:830840.

3 Heusch G, Kleinbongard P, Bose D, Levkau B, Haude M, Schulz R, Erbel R: Coronary Microembolization From Bedside to Bench and Back to Bedside. Circulation 2009;120:1822-1836.

4 Breuckmann F, Nassenstein K, Bucher C, Konietzka I, Kaiser G, Konorza T, Naber C, Skyschally A, Gres P, Heusch G, Erbel R, Barkhausen J: Systematic Analysis of Functional and Structural Changes After Coronary Microembolization: A Cardiac Magnetic Resonance Imaging Study. JACC Cardiovasc Imaging 2009;2:121130.

-5 Heusch G, Schulz R, Haude M, Erbel R: Coronary microembolization. J Mol Cell Cardiol 2004;37:23-31.

6 Pasceri V, Patti G, Di Sciascio G: Prevention of myocardial damage during coronary intervention. Cardiovasc Hematol Disord Drug Targets 2006;6:77-83.

7 Herrmann J: Peri-procedural myocardial injury: 2005 update. Eur Heart J 2005;26:2493-2519.

8 Chen ZW, Qian JY, Ma JY, Chang SF, Yun H, Jin H, Sun AJ, Zou YZ, Ge JB: TNF-alpha-induced cardiomyocyte apoptosis contributes to cardiac dysfunction after coronary microembolization in mini-pigs. J Cell Mol Med 2014;18:1953-1963.

-9 Wang JY, Chen H, Zhou Y, Su Q Liu T, Wang XT, Li L: Atorvastatin Inhibits Myocardial Apoptosis in a Swine Model of Coronary Microembolization by Regulating PTEN/PI3K/Akt Signaling Pathway. Cell Physiol Biochem 2016;38:207-219.

10 Liu T, Zhou Y, Liu YC, Wang JY, Su Q, Tang ZL, Li L: Coronary Microembolization Induces Cardiomyocyte Apoptosis Through the LOX-1-Dependent Endoplasmic Reticulum Stress Pathway Involving JNK/P38 MAPK. Can J Cardiol 2015;31:1272-1281.

-11 Chao W: Toll-like receptor signaling: a critical modulator of cell survival and ischemic injury in the heart. Am J Physiol-Heart C 2009;296:H1-H12.

12 Ostuni R, Zanoni I, Granucci F: Deciphering the complexity of Toll-like receptor signaling. Cell Mol Life Sci 2010;67:4109-4134.

13 Hua F, Ha TZ, Ma J, Li Y, Kelley J, Gao X, Browder IW, Kao RL, Williams DL, Li CF: Protection against myocardial ischemia/reperfusion injury in TLR4-deficient mice is mediated through a phosphoinositide 3-kinase-dependent mechanism. J Immunol 2007;178:7317-7324.

-14 Timmers L, Sluijter JPG, van Keulen JK, Hoefer IE, Nederhoff MGJ, Goumans MJ, Doevendans PA, van Echteld CJA, Joles JA, Quax PH, Piek JJ, Pasterkamp G, de Kleijn DPV: Toll-like receptor 4 mediates maladaptive left ventricular remodeling and impairs cardiac function after myocardial infarction. Circ Res 2008;102:257264.

15 Miller YI: Toll-like receptors and atherosclerosis: oxidized LDL as an endogenous Toll-like receptor ligand. Future Cardiol 2005;1:785-792.

16 Yang K, Wang XQ, Liu ZH, Lu L, Mao JY, Meng H, Wang YN, Hu Y, Zeng Y, Zhang XJ, Chen QJ, Liu Y, Shen WF: Oxidized Low-Density Lipoprotein Promotes Macrophage Lipid Accumulation via the Toll-Like Receptor 4-Src Pathway. Circ J 2015;79:2509-2516.

17 Guo L, Chen CH, Zhang LL, Cao XJ, Ma QL, Deng P, Zhu G, Gao CY, Li BH, Pi Y, Liu Y, Hu ZC, Zhang L, Yu ZP, Zhou Z, Li JC: IRAK1 mediates TLR4-induced ABCA1 downregulation and lipid accumulation in VSMCs. Cell Death Dis 2015;6:e1949. 


\section{Cellular Physiology Cell Physiol Biochem 2017;41:1675-1683 \begin{tabular}{ll|l} 
DOI: 10.1159/000471248 & and Biochemistry \\
Publisned onnine:1Varch 29, 2017 & $\begin{array}{l}\text { O 2017 The Author(s). Published by S. Karger AG, Basel } \\
\text { www.karger.com/cpb }\end{array}$
\end{tabular}}

Wang et al.: Effects of TAK-242 on CME-Induced Myocardial Injury

18 Wang XT, Sun YH, Yang HF, Lu YX, Li L: Oxidized Low-Density Lipoprotein Induces Apoptosis in Cultured Neonatal Rat Cardiomyocytes by Modulating the TLR4/NF-kappa B Pathway. Sci Rep 2016;6:27866.

19 Li L, Li DH, Qu N, Wen WM, Huang WQ: The Role of ERK1/2 Signaling Pathway in Coronary Microembolization-Induced Rat Myocardial Inflammation and Injury. Cardiology 2010;117:207-215.

20 Li L, Zhao XM, Lu YG, Huang WQ, Wen WM: Altered expression of pro- and anti-inflammatory cytokines is associated with reduced cardiac function in rats following coronary microembolization. Mol Cell Biochem 2010;342:183-190.

-21 Zhang YD, Peng WS, Ao X, Dai HY, Yuan L, Huang XZ, Zhou QL: TAK-242, a Toll-Like Receptor 4 Antagonist, Protects against Aldosterone-Induced Cardiac and Renal Injury. Plos One 2015;10:e0142456.

-22 Li L, Su Q, Wang Y, Su B, Dai RX, Lu YG, Wu XH, Liu TW: [Cardiomyocyte apoptosis and death receptor pathway in a rat model of coronary microembolization]. Zhonghua xin xue guan bing za zhi 2010;38:363368.

23 Morishima I, Sone T, Okumura K, Tsuboi H, Kondo J, Mukawa H, Matsui H, Toki Y, Ito T, Hayakawa T: Angiographic no-reflow phenomenon as a predictor of adverse long-term outcome in patients treated with percutaneous transluminal coronary angioplasty for first acute myocardial infarction. J Am Coll Cardiol 2000;36:1202-1209.

24 Riad A, Jager S, Sobirey M, Escher F, Yaulema-Riss A, Westermann D, Karatas A, Heiirnesaat MM, Bereswill S, Dragun D, Pauschinger M, Schultheiss HP, Tschope C: Toll-like receptor-4 modulates survival by induction of left ventricular remodeling after myocardial infarction in mice. J Immunol 2008;180:6954-6961.

25 Yang J, Guo X, Yang J, Ding JW, Li S, Yang R, Fan ZX, Yang CJ: RP105 Protects Against Apoptosis in Ischemia/ Reperfusion-Induced Myocardial Damage in Rats by Suppressing TLR4-Mediated Signaling Pathways. Cell Physiol Biochem 2015;36:2137-2148.

-26 Meng Z, Yan C, Deng Q, Dong X, Duan ZM, Gao DF, Niu XL: Oxidized Low-Density Lipoprotein Induces Inflammatory Responses in Cultured Human Mast Cells Via Toll-Like Receptor 4. Cell Physiol Biochem 2013;31:842-853.

27 Xu Y, Kong X, Zhou H, Zhang X, Liu J, Yan J, Xie H, Xie Y: oxLDL/beta2GPI/anti-beta2GPI complex induced macrophage differentiation to foam cell involving TLR4/NF-kappa B signal transduction pathway. Thromb Res 2014;134:384-392.

28 Barton GM, Medzhitov R: Toll-like receptor signaling pathways. Science 2003;300:1524-1525.

29 Hu ZP, Fang XL, Fang N, Wang XB, Qian HY, Cao Z, Cheng Y, Wang BN, Wang Y: Melatonin ameliorates vascular endothelial dysfunction, inflammation, and atherosclerosis by suppressing the TLR4/NF-kappa B system in high-fat-fed rabbits. J Pineal Res 2013;55:388-398.

-30 Li T, Yu J, Chen R, Wu J, Fei J, Bo Q, Xue L, Li D: Mycophenolate mofetil attenuates myocardial ischemiareperfusion injury via regulation of the TLR4/NF-kappaB signaling pathway. Pharmazie 2014;69:850-855.

- 31 Su HL, Gorodny N, Gomez LF, Gangadharmath U, Mu FR, Chen G, Walsh JC, Szardenings K, Kolb HC, Tamarappoo B: Noninvasive Molecular Imaging of Apoptosis in a Mouse Model of Anthracycline-Induced Cardiotoxicity. Circ Cardiovasc Imaging 2015;8:e001952. 